\title{
Parabrachial Complex: A Hub for Pain and Aversion
}

\author{
Michael C. Chiang, ${ }^{1}$ Anna Bowen, ${ }^{2}$ Lindsey A. Schier, ${ }^{3}$ Domenico Tupone,${ }^{4,6}$ Olivia Uddin, ${ }^{5}$ and Mary M. Heinricher ${ }^{6,7}$ \\ ${ }^{1}$ Department Neurobiology, University of Pittsburgh, Pittsburgh, Pennsylvania, 15213, ${ }^{2}$ Graduate Program in Neuroscience, University of Washington, \\ Seattle, Washington, 98195, ${ }^{3}$ Department Biological Sciences, University of Southern California, Los Angeles, California, 90089, ${ }^{4}$ Biomedical and \\ Neuromotor Sciences, University of Bologna, 40126 Bologna, Italy, ${ }^{5}$ Department of Anatomy and Neurobiology, University of Maryland, Baltimore, \\ Maryland, 21201, ${ }^{6}$ Department Neurological Surgery, Oregon Health and Science University, Portland, Oregon, 97239, and ${ }^{7}$ Department Behavioral \\ Neuroscience, Oregon Health and Science University, Portland, Oregon, 97239
}

The parabrachial nucleus (PBN) has long been recognized as a sensory relay receiving an array of interoceptive and exteroceptive inputs relevant to taste and ingestive behavior, pain, and multiple aspects of autonomic control, including respiration, blood pressure, water balance, and thermoregulation. Outputs are known to be similarly widespread and complex. How sensory information is handled in PBN and used to inform different outputs to maintain homeostasis and promote survival is only now being elucidated. With a focus on taste and ingestive behaviors, pain, and thermoregulation, this review is intended to provide a context for analysis of PBN circuits involved in aversion and avoidance, and consider how information of various modalities, interoceptive and exteroceptive, is processed within PBN and transmitted to distinct targets to signal challenge, and to engage appropriate behavioral and physiological responses to maintain homeostasis.

Key words: alarm; defense; thermoregulation; taste; nociception; brainstem

\section{PBN as a sensory hub for pain and aversion}

Interest in brain circuits mediating reward goes back decades, stimulated by the discovery that animals would work to activate specific brain pathways, a recognition of the adaptive value of positive affect in motivating adaptive behaviors, such as feeding or mating, and increasing appreciation of the role of these pathways in drug abuse (White and Franklin, 1989; Koob and Le Moal, 2001). By contrast, central circuits mediating aversion and avoidance have lacked a central focus, although these defensive behaviors have equal adaptive value. Damaging or potentially damaging stimuli require behavioral and physiological responses that minimize exposure to the noxious event and support learning that allows avoidance of future encounters. Regardless of the modality of the noxious stimulus, hardwired neural connections permit appropriate physiological responses that begin with adaptive behavioral and autonomic changes within the acute setting, followed by the emergence of learned avoidance behavior. A growing body of work points to the parabrachial complex (PBN) as an evolutionarily conserved hindbrain structure that allows a variety of threats to be linked to an appropriate configuration of behavioral and physiological responses (Fulwiler and Saper, 1984; Bernard and Bandler, 1998; Fuller et al., 2011; Nakamura and Morrison, 2011; Kaur et al., 2013). The present review con-

Received June 24, 2019; revised July 29, 2019; accepted Aug. 3, 2019.

This work was supported by National Institutes of Health Grant T32NS099578 to A.B., Grants F30 NS096860, T32 GM008208, AR063772, and NS096705 to M.C.C., Grants DA042565 and NS098660 to M.M.H., Grant NS099234 to D.T., and Grant NS099245 to 0.U. D.T. was also supported by the Rita Levi Montalcini Programme. L.A.S. was supported by University of Southern California Dornsife College of Letters, Arts and Sciences.

The authors declare no competing financial interests.

Correspondence should be addressed to Mary M. Heinricher at heinricm@ohsu.edu.

https://doi.org/10.1523/JNEUROSCI.1162-19.2019

Copyright $\odot 2019$ the authors siders PBN as a "hub" for pain and aversion, with a focus on contributions to pain, bad taste and regulation of ingestive behaviors, and thermoregulatory challenge.

The PBN is a cell grouping that surrounds the superior cerebellar peduncles in the dorsolateral pons. In rodent, PBN can be divided into more than a dozen subnuclei on the basis of cytoarchitecture (Fulwiler and Saper, 1984). Medial PBN (mPBN) comprises populations of neurons heterogeneous in size and morphology, whereas lateral PBN (lPBN) includes several homogeneous groups. The cytoarchitecturally defined subdivisions within $\mathrm{MPBN}$ and IPBN are also marked by differential connectivity and neurochemistry. Figure 1 provides a schematic of major subnuclei and some important inputs and output of PBN. The majority of PBN neurons are glutamatergic, although a significant population is GABAergic (Geerling et al., 2017). There are numerous peptides colocalized with both populations, including calcitonin gene-related peptide (CGRP), substance P, neurotensin, and dynorphin. Cytoarchitectural organization in primates, including humans, is similar, although fewer subnuclei have been delineated (Kitamura et al., 2001; Paxinos et al., 2009).

The PBN receives input from sensory systems (Fig. 1), as well as from higher brain areas. Sensory input relevant to taste and other viscerosensory modalities, respiratory control, fluid balance, and cardiovascular function is derived primarily from the nucleus of the solitary tract (Herbert et al., 1990). Additional inputs relevant to respiratory control arise from brainstem chemosensory neurons (Rosin et al., 2006). Nociceptive, pruritic, and thermal information is directed to IPBN via the spinoparabrachial tract from the trigeminal and spinal dorsal horns (Hylden et al., 1985; Craig, 1995; Cameron et al., 2015; Rodriguez et al., 2017; Morrison and Nakamura, 2019). PBN also has reciprocal connections with structures throughout the brain, consis- 
tent with a role in integrating sensory information with behavior and autonomic function. For example, $\mathrm{PBN}$ is reciprocally connected with CeA, BNST, and multiple hypothalamic nuclei, including the preoptic area. Other major outputs from PBN include the paraventricular and gustatory thalamus, and the insular and infralimbic/prelimbic cortex (Tokita et al., 2010; Saper and Loewy, 2016; Morrison and Nakamura, 2019). Projections within the brainstem include reticular motor areas (Geerling et al., 2017; Barik et al., 2018) and the rostral ventromedial medulla (RVM), the latter an area implicated in both pain modulation and thermogenesis (Roeder et al., 2016; Chen et al., 2017; Morrison and Nakamura, 2019). Recent technical advances are allowing increasingly detailed delineation of the function(s) of distinct inputs to and outputs from PBN, some of which will be considered below.

\section{Role of PBN in taste-guided behavior}

Although health and survival depend upon eating and drinking, these acts carry inherent risks, such as poisoning, food allergy, and nutrient intolerance. To cope with these threats, the mammalian gustatory system has evolved specialized chemoreceptors (or taste receptors) that act as the ultimate guardians of the gastrointestinal tract. Upon binding their respective ligands, these receptors elicit a signal that is channeled into appropriate response outputs. For instance, one family of taste receptors (the T2Rs) bind a vast array of bitter ligands, which tend to be toxic. Activation of the T2Rs unconditionally drives rejective behaviors and deters further ingestion (Adler et al., 2000; Chandrashekar et al., 2000; Matsunami et al., 2000; Schier and Spector, 2019). While these hardwired circuits linked to the sensory properties of food offer a great deal of protection, they are not failsafe. Noxious chemicals can be cloaked in an otherwise palatable food, whereas essential nutrients or medicinal substances are sometimes packaged with a nonlethal bitterant (e.g., cruciferous vegetables). The body's ability to associate the orosensory properties of a food or fluid with its actual postingestive consequences, and to adjust behavioral and physiological responses in ways that maximize the benefit while minimizing the risks, are therefore critical for health and survival.

A key feature of the gustatory and visceroceptive systems facilitates the link between taste and postingestive consequences. Visceroceptive events, such as food poisoning or nutrient malabsorption, have privileged access to the gustatory system. This was demonstrated $>50$ years ago with a series of experiments from Garcia, Koelling, and others (Garcia et al., 1955; Garcia and Koelling, 1966). These experiments showed that rats rapidly learned to avoid a flavor that had been paired with certain negative gastrointestinal events, such as the emetic agent lithium chloride $(\mathrm{LiCl})$ or irradiation. This phenomenon is now called conditioned taste aversion. The association is selective in that rats do not display similar expediency in learning to avoid a flavor paired with a negative exteroceptive event, such as foot shock.

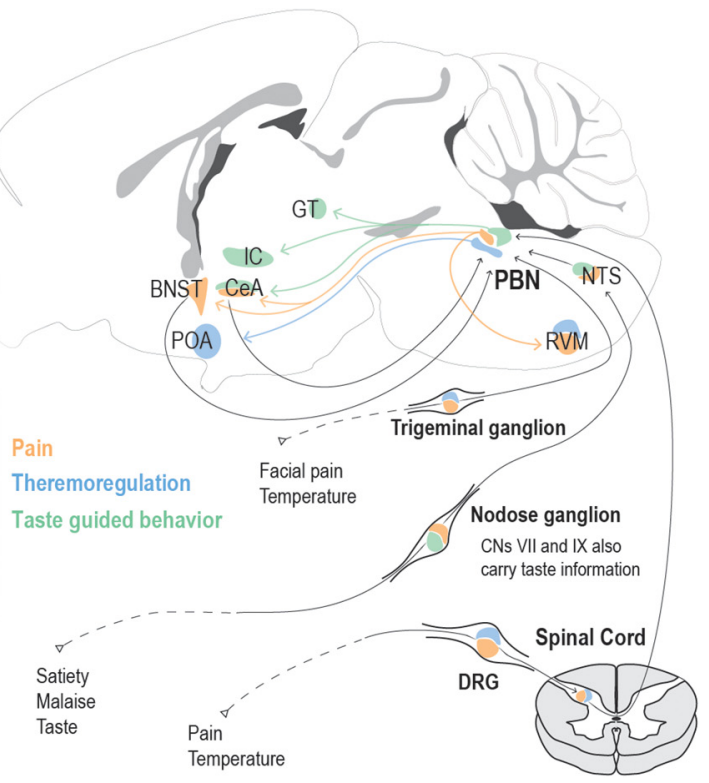

Figure 1. Pathways to and from the parabrachial complex that mediate taste-guided behavior, and contribute to pain and Pe parabrachial complex are as follows: dl, Dorsal lateral; el, external lateral; sl, superior lateral; $\mathrm{Cl}$, central lateral; $\mathrm{vl}$, ventral lateral; $\mathrm{m}$, medial; BNST; CeA; IC, insular cortex; GT; KF, Kölliker Fuse; POA, preoptic area; RVM; scp, superior cerebellar peduncle.

Conversely, rats can readily learn to pair a tone or light with foot shock, but are less susceptible to associations between these exteroceptive cues (tone, light) and negative internal gastrointestinal events. Collectively, these studies imply an underlying organization that facilitates integration of specific sensory inputs with each other (e.g., taste, smell, visceroceptive), and links those to specific motor outputs (e.g., rejection).

Lesions of PBN attenuate various aspects of taste-guided behavior, including conditioned taste aversion, salt appetite, and preference (Hill and Almli, 1983; Flynn et al., 1991; Spector, 1995; Grigson et al., 2015), pointing to PBN as a link between taste and ingestive behavior. PBN has also been implicated in suppression of feeding based on postingestive signals. The region is thought to contribute to satiety as part of a negative feedback system with excitatory input from nucleus of the solitary tract neurons that relay interoceptive signals, including gastric distension and postprandial peptides (e.g., cholecystokinin), both of which activate vagal afferent neurons innervating the alimentary canal. The output from $\mathrm{PBN}$ is presumed to suppress appetitive drive by relaying a negative valence signal to the forebrain, where it both counteracts the hedonic value of the food and suppresses motivational drive to consume (Chambers et al., 2013). This negative feedback signal is normally activated only transiently, as a homeostatic mechanism following a meal.

$\mathrm{PBN}$ can also be recruited in malaise, as an adaptive component of the sickness response (Kent et al., 1996; Kelley et al., 2003; Chaskiel et al., 2016). A recent series of studies demonstrated that a subpopulation of $1 \mathrm{PBN}$ neurons that respond to negative visceral stimuli, such as $\mathrm{LiCl}$, project to CeA and the BNST (Carter et al., 2013, 2015; Roman et al., 2017), and that manipulation of 
external lateral PBN (elPBN) neurons projecting to the CeA greatly diminished the effect of these negative stimuli on food intake. By contrast, manipulation of the connection with the BNST pathway had no effect on intake (Carter et al., 2013).

One shortcoming of the above findings is that most studies were limited to measures of intake. Such measures do not allow us to discern whether a particular food is aversive, meaning that it has a negative hedonic valence, or merely avoided, meaning that it elicits a motor repertoire that allows the organism to steer clear of a potentially harmful substance (Davis and Levine, 1977; Spector and Glendinning, 2009; Schier and Spector, 2019). In nonverbal experimental animals, like the rat, we must depend on a complement of behavioral procedures to differentiate aversion from avoidance and to uncover the motivational bases and neural circuitry involved. One approach is the taste reactivity test, which measures the stereotypic oromotor reflexes elicited by stimulation of the taste receptors, and is a more useful readout of potentially aversive qualities of a given taste than consumption per se (Grill and Norgren, 1978). Studies using this behavioral assay demonstrate that taste avoidance is not necessarily accompanied by taste aversion (Pelchat et al., 1983; Schier et al., 2019). Given this distinction, it will be useful to determine whether and how PBN contributes to aversion versus avoidance of specific tasterelated and postingestive signals.

\section{PBN and pain}

PBN, particularly IPBN, has an important role in receiving, processing, and relaying somatic and visceral nociceptive signals (Gauriau and Bernard, 2002). It is the primary supraspinal target of nociceptive transmission neurons with cell bodies in the superficial dorsal horn. It also receives projections from deep dorsal horn (Bernard et al., 1995; Feil and Herbert, 1995; Bester et al., 2000; Polgár et al., 2010). Nocireponsive neurons have been identified in IPBN using electrophysiological recording, calcium imaging, and cell activity markers (Bernard and Besson, 1990; Bernard et al., 1994; Hermanson and Blomqvist, 1996; Bourgeais et al., 2001; Campos et al., 2018; Uddin et al., 2018). Interestingly, nociresponsive neurons are concentrated in the external lateral subnucleus, although ascending spinoparabrachial neurons avoid the subnucleus. This mismatch led to the suggestion that intra-PBN interactions are responsible for at least some of the noxious-evoked activations observed in IPBN (Saper, 1995; Bourgeais et al., 2003). This idea was confirmed in a recent analysis showing that dynorphin-expressing neurons in the dorsal lateral subnucleus (dlPBN) with extensive dendritic fields are activated by noxious stimuli and send axons to elPBN (Chiang et al., 2019). In turn, elPBN projects directly to the CeA and BNST and, through a thalamic relay, to the insula, implicating elPBN in both emotional and autonomic aspects of pain (Fulwiler and Saper, 1984; Yasui et al., 1989; Jasmin et al., 1997; Bourgeais et al., 2001). IPBN also projects to the midbrain periaqueductal gray (Gauriau and Bernard, 2002) and to the RVM (Roeder et al., 2016; Chen et al., 2017), both of which are implicated in descending modulation of pain.

\section{PBN and the affective dimension of pain}

It has long been recognized that pain is not simply a sensorydiscriminative phenomenon. Indeed, by definition, the experience of pain has a significant element of unpleasantness and distress. Given the central position of PBN as a sensory relay to a host of forebrain structures important for motivation and emotion, an important question is how PBN contributes to the affective dimension of pain (Gauriau and Bernard, 2002; Neugebauer,
2015). Han et al. (2010) have shown that CGRP-expressing inputs to the CeA from IPBN enhance excitability of neurons in the nociceptive amygdala, and that focal application of exogenous CGRP in CeA to mimic IPBN input produces behavioral hyperalgesia and ultrasonic vocalization, the latter taken as a measure of distress. Recent complementary work in mice shows that stimulation of nociceptive sensory axons activates $1 \mathrm{PBN}$ neurons and induces aversive behaviors, including stress vocalization and avoidance of the location where stimulation occurred (Rodriguez et al., 2017). Consistent with this body of evidence, CGRPexpressing neurons have also been shown to be necessary for the affective component of aversive learning, where a painful stimulus is paired with a specific contextual cue (Han et al., 2015). Viewed as a whole, these data point to IPBN as having an important role in the affective dimension of pain.

\section{Contributions to hyperalgesia and persistent pain}

IPBN makes a relatively limited contribution to acute pain responses, but there is significant evidence for a role for this region in hyperalgesia and persistent pain. This includes the fact that $1 \mathrm{PBN}$ receives its primary nociceptive input from neurokinin 1-expressing neurons in the superficial dorsal horn, a population associated with hyperalgesia in persistent pain due to inflammation or nerve injury (Nichols et al., 1999; Todd et al., 2000; Suzuki et al., 2002; Khasabov et al., 2005; Rivat et al., 2009). More important, there is evidence for reorganization of the connection between IPBN and descending control systems in persistent inflammatory pain models, and blocking IPBN reverses behavioral hypersensitivity under these conditions (Chen and Heinricher, 2019). In addition, $I P B N$ neurons display increased excitability in rodent models of arthritic and neuropathic pain (Matsumoto et al., 1996; Uddin et al., 2018). Interestingly, some mechanically responsive IPBN neurons develop a form of amplified activity known as after-discharges in animals subjected to nerve injury. After-discharges refer to neural responses that far outlast the evoking stimulus, by at least half a second. The proportion of neurons exhibiting after-discharges is increased, and afterdischarges are longer-lasting in nerve-injured animals (Uddin et al., 2018). This hyperexcitability appears in part to reflect a loss of recurrent inhibition from the CeA. CeA not only receives a significant projection from $\mathrm{PBN}$, but also sends a dense inhibitory reciprocal connection back to IPBN. This inhibitory connection from CeA to IPBN is specifically suppressed in slices taken from nerve-injured animals. These electrophysiological observations suggest that loss of inhibition from CeA back to PBN underlies PBN hyperexcitability, and raise the possibility that restoration of this inhibitory connection could reverse behavioral hypersensitivity in persistent pain states.

\section{Distinct outputs from PBN contribute to different aspects of pain}

The widespread distribution of outputs from the PBN suggests that distinct outputs contribute to different aspects of behavioral and physiological responses evoked by the interoceptive and exteroceptive inputs to this complex region. The functions of specific pathways are becoming increasingly tractable with optogenetic tools that allow differential manipulation of specific terminal projections arising from PBN. Using this approach, Barik et al. (2018) provided evidence that projections to the caudaldorsal medullary reticular formation, an area long implicated in motor function (Peterson, 1979), arise from tachykinin1positive neurons in $1 \mathrm{PBN}$. Activation of this projection facilitated motor responses evoked by noxious stimulation, particularly 
during inflammation. In another series of studies, Chiang et al. (2019) analyzed PBN projections to ventromedial hypothalamus and lateral periaqueductal gray, and to CeA and BNST. The former arose primarily from dlPBN, and the latter from elPBN. Stimulation of the projections to ventromedial hypothalamus and periaqueductal gray elicited running and jumping. Activation of the projection to the periaqueductal gray also produced analgesia. In contrast, stimulation of the connections with CeA and BNST drove avoidance behavior (real-time place aversion) and aversive learning. Each of these effects is consistent with the known effect of stimulating the target structure directly. These findings further reinforce the idea of $\mathrm{PBN}$ as a "hub" linking interoceptive and exteroceptive sensory information to appropriate responses.

PBN has also been described as linking ascending paintransmission pathways with descending pain-modulation pathways, including the periaqueductal gray-RVM circuit that has been implicated in both analgesia (including opioid analgesia) and hyperalgesia and persistent pain states (Heinricher and Fields, 2013; Chen and Heinricher, 2018). As already noted, IPBN projects densely to the periaqueductal gray, and stimulation of IPBN terminals in the periaqueductal gray produces analgesia (Chiang et al., 2019), as does direct stimulation of periaqueductal gray itself (Heinricher and Fields, 2013). By contrast, the IPBN output to the RVM exerts a net pronociceptive effect, which is most pronounced in persistent pain states (Chen and Heinricher, 2019).

\section{PBN and cold defense}

Just as pain serves as a warning signal for preserving bodily integrity, and taste serves as a signal for potentially noxious foods, thermosensory information informs behavioral and autonomic thermoregulatory mechanisms that maintain core body temperature within a narrow acceptable range. This sensory input is conveyed from the skin by primary afferent thermoreceptors, and relayed through the superficial dorsal horn to higher structures, including PBN. PBN contributes to both thermoregulatory behaviors and autonomic responses to skin warming or cooling (Morrison and Nakamura, 2019).

PBN outputs for behavioral thermoregulation are not fully understood, but projections to hypothalamic centers, particularly the preoptic area, mediate autonomic components of thermoregulation. Cold thermal information is relayed through the elPBN to recruit shivering and nonshivering thermogenesis, whereas warm information is conveyed by dlPBN neurons and inhibits thermogenesis, presumably via dynorphinergic outputs (Geerling et al., 2016; Morrison and Nakamura, 2019).

In mammals, behavioral thermoregulation is one of the main mechanisms for coping with a thermally challenging environment, whether cooler or warmer than optimal. When behavioral coping is not sufficient, autonomic circuits also help regulate and maintain core body temperature within an acceptable range. However, there are situations where these two mechanisms are insufficient. One such challenge is extreme cold combined with lack of food, a situation in which the sustained thermogenesis that would be required to maintain normal body temperature would drain energy reserves, potentially resulting in death. Some mammals have developed the ability to escape this dangerous situation by entering a state of hibernation (Nedergaard and Cannon, 1990). By reducing metabolism and allowing core body temperature to fall, hibernation allows these animals to survive a harsh winter. Hibernation is marked by an inverted thermoregulatory response in which cold exposure suppresses, rather than promotes, thermogenesis (Tupone et al., 2017). Development of an experimen- tal model of thermoregulatory inversion in rat, a nonhibernating species, has allowed investigation of the neural circuits underlying this thermoregulatory switch (Tupone et al., 2013).

Studies using selective inactivation suggest that, while dlPBN is essential for cold-induced inhibition of thermogenesis, the relevant cell population and projection target are distinct from those involved under normal conditions in which cold elicits thermogenesis (Tupone et al., 2018). Although how the choice of normal versus inverted thermoregulation is made at the level of PBN remains unclear, it is evident that a need to align thermoregulatory output with other homeostatistic functions, particularly energy metabolism, is a key driver of the switch between the two circuits. Delineation of PBN circuits contributing to normal and inverted thermoregulation could therefore help elucidate integrative principles within the PBN. It is nonetheless reasonable to suggest that the convergence of cardiovascular, respiratory, metabolic, and nociceptive information in PBN enables integration of multiple sources of information that determines whether a behavioral strategy, autonomic thermoregulation, or hibernation is chosen as the appropriate response in a given environment and state of the body.

\section{$\mathrm{PBN}$ as a contributor to general alarm, with a specific role for CGRP-expressing neurons in elPBN}

The recognition that $\mathrm{PBN}$ plays a role in a range of defensive responses to potential threats of various modalities was recently brought together with a proposal that a subpopulation of CGRPexpressing neurons in elPBN functions as a general alarm (Palmiter, 2018). This conceptual framework was inspired by the finding that CGRP-expressing IPBN neurons are required for the starvation phenotype resulting from ablation of hypothalamic neurons expressing agouti-related peptide (Wu et al., 2012). Inhibition of CGRP-expressing neurons in elPBN restored food intake in these animals (Carter et al., 2013) and also prevented anorexia in visceral illness, malaise, and cancer cachexia (Carter et al., 2013; Campos et al., 2017). Together with evidence that CGRP-expressing $1 \mathrm{PBN}$ neurons projecting to CeA have a significant role in the affective dimension of pain and contribute to hyperalgesia in persistent pain states (Neugebauer et al., 2004), and that these neurons have a role in other protective responses (Mu et al., 2017), for example, chemosensory arousal and itch (Kaur et al., 2017), it has been proposed that CGRP-expressing neurons in elPBN generate a multimodal threat signal that engages defensive behaviors (Palmiter, 2018).

In conclusion, as should be apparent from this brief review, even when considered within the relatively limited confines of ingestive behavior, pain, and thermoregulation, $\mathrm{PBN}$ receives multiple inputs, plays a role in multiple functions relevant to homeostasis and the state of the body, and contributes to distinct behavioral and motivational outputs. Investigators are now taking a more holistic view of PBN, and starting to seek organizing principles with which to understand the function of this complex region. The idea of a specific subset of $1 \mathrm{PBN}$ neurons serving as a general alarm is an important step in this direction, with the idea that sensory signals related to threat generate a scalable, intermodal intensity signal that engages appropriate circuits to elicit defensive responding. Despite recent advances, a host of questions remain. First, PBN is by no means limited to processing only information related to aversive and painful stimuli. For example, $\mathrm{PBN}$ has long been known to play a role in taste preference as well as taste aversion (Yamamoto et al., 1994; Han et al., 2018; Fu et al., 2019), and understanding when and how positive hedonic valence is processed in PBN remains much less explored. It 
would be interesting, for example, to determine whether this region has a role in pleasurable touch. Second, $\mathrm{PBN}$ is embedded within a complex web of connections spanning lower medulla to neocortex. Whether different projections have distinct sources and functions is only now starting to be considered, a task that is greatly facilitated by modern circuit analytical tools that allow dissection of specific populations within PBN as well as inputs and outputs. Indeed, the identification of neurochemical markers and neuropeptides within distinct PBN subnuclei is providing increasing insights into the organization of PBN circuitry. However, caution is warranted when making the assumption that all neurons expressing a given marker share a common function. Third, it must be acknowledged that our knowledge of PBN derives primarily from studies in rodent, although spinoparabrachial projections have been identified in primate (Craig, 1995), and functional imaging reveals activation of the $\mathrm{PBN}$ region during activation of viscerosensory and nociceptive systems (Topolovec et al., 2004; Dunckley et al., 2005; Youssef et al., 2016). Finally, almost nothing is known of the internal organization of PBN. How, or even whether, sensory information is integrated within PBN to contribute to the coordinated behavioral and physiological responses required in challenging environments is only beginning to be explored (Alhadeff et al., 2018). Individual neurons within PBN apparently receive multimodal information (see, e.g., Fu et al., 2019 or Campos et al., 2018) but contribute to coordinated and differentiated behavioral and autonomic outputs. This convergence raises the possibility that different populations of PBN neurons integrate multiple forms of sensory information to determine the appropriate physiological adjustments and behavioral strategies.

\section{References}

Adler E, Hoon MA, Mueller KL, Chandrashekar J, Ryba NJ, Zuker CS (2000) A novel family of mammalian taste receptors. Cell 100:693-702.

Alhadeff AL, Su Z, Hernandez E, Klima ML, Phillips SZ, Holland RA, Guo C, Hantman AW, De Jonghe BC, Betley JN (2018) A neural circuit for the suppression of pain by a competing need state. Cell 173:140-152.e15.

Barik A, Thompson JH, Seltzer M, Ghitani N, Chesler AT (2018) A brainstem-spinal circuit controlling nocifensive behavior. Neuron 100: 1491-1503.e3.

Bernard JF, Bandler R (1998) Parallel circuits for emotional coping behaviour: new pieces in the puzzle. J Comp Neurol 401:429-436.

Bernard JF, Besson JM (1990) The spino(trigemino)pontoamygdaloid pathway: electrophysiological evidence for an involvement in pain processes. J Neurophysiol 63:473-490.

Bernard JF, Huang GF, Besson JM (1994) The parabrachial area: electrophysiological evidence for an involvement in visceral nociceptive processes. J Neurophysiol 71:1646-1660.

Bernard JF, Dallel R, Raboisson P, Villanueva L, Le Bars D (1995) Organization of the efferent projections from the spinal cervical enlargement to the parabrachial area and periaqueductal gray: a PHA-L study in the rat. J Comp Neurol 353:480-505.

Bester H, Chapman V, Besson JM, Bernard JF (2000) Physiological properties of the lamina I spinoparabrachial neurons in the rat. J Neurophysiol 83:2239-2259.

Bourgeais L, Monconduit L, Villanueva L, Bernard JF (2001) Parabrachial internal lateral neurons convey nociceptive messages from the deep laminas of the dorsal horn to the intralaminar thalamus. J Neurosci 21:2159-2165.

Bourgeais L, Gauriau C, Monconduit L, Villanueva L, Bernard JF (2003) Dendritic domains of nociceptive-responsive parabrachial neurons match terminal fields of lamina I neurons in the rat. J Comp Neurol 464:238-256.

Cameron D, Polgár E, Gutierrez-Mecinas M, Gomez-Lima M, Watanabe M, Todd AJ (2015) The organisation of spinoparabrachial neurons in the mouse. Pain 156:2061-2071.

Campos CA, Bowen AJ, Han S, Wisse BE, Palmiter RD, Schwartz MW (2017) Cancer-induced anorexia and malaise are mediated by CGRP neurons in the parabrachial nucleus. Nat Neurosci 20:934-942.
Campos CA, Bowen AJ, Roman CW, Palmiter RD (2018) Encoding of danger by parabrachial CGRP neurons. Nature 555:617-622.

Carter ME, Soden ME, Zweifel LS, Palmiter RD (2013) Genetic identification of a neural circuit that suppresses appetite. Nature 503:111-114.

Carter ME, Han S, Palmiter RD (2015) Parabrachial calcitonin gene-related peptide neurons mediate conditioned taste aversion. J Neurosci 35:4582-4586.

Chambers AP, Sandoval DA, Seeley RJ (2013) Integration of satiety signals by the central nervous system. Curr Biol 23:R379-R388.

Chandrashekar J, Mueller KL, Hoon MA, Adler E, Feng L, Guo W, Zuker CS, Ryba NJ (2000) T2Rs function as bitter taste receptors. Cell 100:703-711.

Chaskiel L, Paul F, Gerstberger R, Hübschle T, Konsman JP (2016) Brainstem metabotropic glutamate receptors reduce food intake and activate dorsal pontine and medullar structures after peripheral bacterial lipopolysaccharide administration. Neuropharmacology 107:146-159.

Chen Q, Heinricher MM (2018) Unmasking the pain in latent sensitization. Neuroscience 381:159-160.

Chen Q, Heinricher MM (2019) Plasticity in the link between paintransmitting and pain-modulating systems in acute and persistent inflammation. J Neurosci 39:2065-2079.

Chen Q, Roeder Z, Li MH, Zhang Y, Ingram SL, Heinricher MM (2017) Optogenetic evidence for a direct circuit linking nociceptive transmission through the parabrachial complex with pain-modulating neurons of the rostral ventromedial medulla (RVM). eNeuro 4:ENEURO.0202-17.2017.

Chiang MC, Nguyen EK, Papale AE, Ross SE (2019) Divergent neural pathways emanating from the lateral parabrachial nucleus mediate distinct components of the pain response. BioRxiv. 602466.

Craig AD (1995) Distribution of brainstem projections from spinal lamina I neurons in the cat and the monkey. J Comp Neurol 361:225-248.

Davis JD, Levine MW (1977) A model for the control of ingestion. Psychol Rev 84:379-412.

Dunckley P, Wise RG, Fairhurst M, Hobden P, Aziz Q, Chang L, Tracey I (2005) A comparison of visceral and somatic pain processing in the human brainstem using functional magnetic resonance imaging. J Neurosci 25:7333-7341.

Feil K, Herbert H (1995) Topographic organization of spinal and trigeminal somatosensory pathways to the rat parabrachial and Kölliker-Fuse nuclei. J Comp Neurol 353:506-528.

Flynn FW, Grill HJ, Schwartz GJ, Norgren R (1991) Central gustatory lesions: I. Preference and taste reactivity tests. Behav Neurosci 105:933-943.

Fu O, Iwai Y, Kondoh K, Misaka T, Minokoshi Y, Nakajima KI (2019) SatB2-expressing neurons in the parabrachial nucleus encode sweet taste. Cell Rep 27:1650-1656.e4.

Fuller PM, Sherman D, Pedersen NP, Saper CB, Lu J (2011) Reassessment of the structural basis of the ascending arousal system. J Comp Neurol 519: 933-956.

Fulwiler CE, Saper CB (1984) Subnuclear organization of the efferent connections of the parabrachial nucleus in the rat. Brain Res 319:229-259.

Garcia J, Koelling RA (1966) Relation of cue to consequence in avoidance learning. Psychonom Sci 4:123-124.

Garcia J, Kimeldorf DJ, Koelling RA (1955) Conditioned aversion to saccharin resulting from exposure to gamma radiation. Science 122:157-158.

Gauriau C, Bernard JF (2002) Pain pathways and parabrachial circuits in the rat. Exp Physiol 87:251-258.

Geerling JC, Kim M, Mahoney CE, Abbott SB, Agostinelli LJ, Garfield AS, Krashes MJ, Lowell BB, Scammell TE (2016) Genetic identity of thermosensory relay neurons in the lateral parabrachial nucleus. Am J Physiol Regul Integr Comp Physiol 310:R41-R54.

Geerling JC, Yokota S, Rukhadze I, Roe D, Chamberlin NL (2017) KöllikerFuse GABAergic and glutamatergic neurons project to distinct targets. J Comp Neurol 525:1844-1860.

Grigson PS, Colechio EM, Power ML, Schulkin J, Norgren R (2015) Parabrachial lesions in rats disrupt sodium appetite induced by furosemide but not by calcium deprivation. Physiol Behav 140:172-179.

Grill HJ, Norgren R (1978) The taste reactivity test: I. Mimetic responses to gustatory stimuli in neurologically normal rats. Brain Res 143:263-279.

Han JS, Adwanikar H, Li Z, Ji G, Neugebauer V (2010) Facilitation of synaptic transmission and pain responses by CGRP in the amygdala of normal rats. Mol Pain 6:10.

Han S, Soleiman MT, Soden ME, Zweifel LS, Palmiter RD (2015) Elucidating an affective pain circuit that creates a threat memory. Cell 162:363-374.

Han W, Tellez LA, Perkins MH, Perez IO, Qu T, Ferreira J, Ferreira TL, Quinn D, Liu ZW, Gao XB, Kaelberer MM, Bohórquez DV, Shammah-Lagnado 
SJ, de Lartigue G, de Araujo IE (2018) A neural circuit for gut-induced reward. Cell 175:665-678.e23.

Heinricher MM, Fields HL (2013) Central nervous system mechanisms of pain modulation. In: Wall and Melzack's textbook of pain, Ed 6 (McMahon S, Koltzenburg M, Tracey I, Turk DC, eds), pp 129-142. London: Elsevier.

Herbert H, Moga MM, Saper CB (1990) Connections of the parabrachial nucleus with the nucleus of the solitary tract and the medullary reticular formation in the rat. J Comp Neurol 293:540-580.

Hermanson O, Blomqvist A (1996) Subnuclear localization of FOS-like immunoreactivity in the rat parabrachial nucleus after nociceptive stimulation. J Comp Neurol 368:45-56.

Hill DL, Almli CR (1983) Parabrachial nuclei damage in infant rats produces residual deficits in gustatory preferences/aversions and sodium appetite. Dev Psychobiol 16:519-533.

Hylden JL, Hayashi H, Bennett GJ, Dubner R (1985) Spinal lamina I neurons projecting to the parabrachial area of the cat midbrain. Brain Res 336:195-198.

Jasmin L, Burkey AR, Card JP, Basbaum AI (1997) Transneuronal labeling of a nociceptive pathway, the spino-(trigemino-)parabrachio-amygdaloid, in the rat. J Neurosci 17:3751-3765.

Kaur S, Pedersen NP, Yokota S, Hur EE, Fuller PM, Lazarus M, Chamberlin NL, Saper CB (2013) Glutamatergic signaling from the parabrachial nucleus plays a critical role in hypercapnic arousal. J Neurosci 33:7627-7640.

Kaur S, Wang JL, Ferrari L, Thankachan S, Kroeger D, Venner A, Lazarus M, Wellman A, Arrigoni E, Fuller PM, Saper CB (2017) A genetically defined circuit for arousal from sleep during hypercapnia. Neuron 96:1153-1167.e5.

Kelley KW, Bluthe RM, Dantzer R, Zhou JH, Shen WH, Johnson RW, Broussard SR (2003) Cytokine-induced sickness behavior. Brain Behav Immun 17 [Suppl 1]:S112-S118.

Kent S, Bret-Dibat JL, Kelley KW, Dantzer R (1996) Mechanisms of sickness-induced decreases in food-motivated behavior. Neurosci Biobehav Rev 20:171-175.

Khasabov SG, Ghilardi JR, Mantyh PW, Simone DA (2005) Spinal neurons that express NK-1 receptors modulate descending controls that project through the dorsolateral funiculus. J Neurophysiol 93:998-1006.

Kitamura T, Nagao S, Kunimoto K, Shirama K, Yamada J (2001) Cytoarchitectonic subdivisions of the parabrachial nucleus in the Japanese monkey (Macacus fuscatus) with special reference to spinoparabrachial fiber terminals. Neurosci Res 39:95-108.

Koob GF, Le Moal M (2001) Drug addiction, dysregulation of reward, and allostasis. Neuropsychopharmacology 24:97-129.

Matsumoto N, Bester H, Menendez L, Besson JM, Bernard JF (1996) Changes in the responsiveness of parabrachial neurons in the arthritic rat: an electrophysiological study. J Neurophysiol 76:4113-4126.

Matsunami H, Montmayeur JP, Buck LB (2000) A family of candidate taste receptors in human and mouse. Nature 404:601-604.

Morrison SF, Nakamura K (2019) Central mechanisms for thermoregulation. Annu Rev Physiol 81:285-308.

Mu D, Deng J, Liu KF, Wu ZY, Shi YF, Guo WM, Mao QQ, Liu XJ, Li H, Sun YG (2017) A central neural circuit for itch sensation. Science 357:695-699.

Nakamura K, Morrison SF (2011) Central efferent pathways for colddefensive and febrile shivering. J Physiol 589:3641-3658.

Nedergaard J, Cannon B (1990) Mammalian hibernation. Philos Trans R Soc Lond B Biol Sci 326:669-685, discussion 685-686.

Neugebauer V (2015) Amygdala pain mechanisms. Handb Exp Pharmacol 227:261-284.

Neugebauer V, Li W, Bird GC, Han JS (2004) The amygdala and persistent pain. Neuroscientist 10:221-234.

Nichols ML, Allen BJ, Rogers SD, Ghilardi JR, Honore P, Luger NM, Finke MP, Li J, Lappi DA, Simone DA, Mantyh PW (1999) Transmission of chronic nociception by spinal neurons expressing the substance P receptor. Science 286:1558-1561.

Palmiter RD (2018) The parabrachial nucleus: CGRP neurons function as a general alarm. Trends Neurosci 41:280-293.

Paxinos G, Huang XF, Petrides M, Toga AW (2009) The rhesus monkey brain in stereotaxic coordinates, Ed 2. San Diego: Academic.

Pelchat ML, Grill HJ, Rozin P, Jacobs J (1983) Quality of acquired responses to tastes by Rattus norvegicus depends on type of associated discomfort. J Comp Psychol 97:140-153.

Peterson BW (1979) Reticulospinal projections to spinal motor nuclei. Annu Rev Physiol 41:127-140.
Polgár E, Wright LL, Todd AJ (2010) A quantitative study of brainstem projections from lamina I neurons in the cervical and lumbar enlargement of the rat. Brain Res 1308:58-67.

Rivat C, Vera-Portocarrero LP, Ibrahim MM, Mata HP, Stagg NJ, De Felice M, Porreca F, Malan TP (2009) Spinal NK-1 receptor-expressing neurons and descending pathways support fentanyl-induced pain hypersensitivity in a rat model of postoperative pain. Eur J Neurosci 29:727-737.

Rodriguez E, Sakurai K, Xu J, Chen Y, Toda K, Zhao S, Han BX, Ryu D, Yin H, Liedtke W, Wang F (2017) A craniofacial-specific monosynaptic circuit enables heightened affective pain. Nat Neurosci 20:1734-1743.

Roeder Z, Chen Q, Davis S, Carlson JD, Tupone D, Heinricher MM (2016) The parabrachial complex links pain transmission to descending pain modulation. Pain 157:2697-2708.

Roman CW, Sloat SR, Palmiter RD (2017) A tale of two circuits: CCK ${ }^{\text {NTS }}$ neuron stimulation controls appetite and induces opposing motivational states by projections to distinct brain regions. Neuroscience 358:316-324.

Rosin DL, Chang DA, Guyenet PG (2006) Afferent and efferent connections of the rat retrotrapezoid nucleus. J Comp Neurol 499:64-89.

Saper CB (1995) The spinoparabrachial pathway: shedding new light on an old path. J Comp Neurol 353:477-479.

Saper CB, Loewy AD (2016) Commentary on: Efferent connections of the parabrachial nucleus in the rat. C. B. Saper and A.D. Loewy, Brain Research 197:291-317, 1980. Brain Res 1645:15-17.

Schier LA, Spector AC (2019) The functional and neurobiological properties of bad taste. Physiol Rev 99:605-663.

Schier LA, Hyde KM, Spector AC (2019) Conditioned taste aversion versus avoidance: a re-examination of the separate processes hypothesis. PLoS One 14:e0217458.

Spector AC (1995) Gustatory parabrachial lesions disrupt taste-guided quinine responsiveness in rats. Behav Neurosci 109:79-90.

Spector AC, Glendinning JI (2009) Linking peripheral taste processes to behavior. Curr Opin Neurobiol 19:370-377.

Suzuki R, Morcuende S, Webber M, Hunt SP, Dickenson AH (2002) Superficial NK1-expressing neurons control spinal excitability through activation of descending pathways. Nat Neurosci 5:1319-1326.

Todd AJ, McGill MM, Shehab SA (2000) Neurokinin 1 receptor expression by neurons in laminae I, III and IV of the rat spinal dorsal horn that project to the brainstem. Eur J Neurosci 12:689-700.

Tokita K, Inoue T, Boughter JD Jr (2010) Subnuclear organization of parabrachial efferents to the thalamus, amygdala and lateral hypothalamus in C57BL/6J mice: a quantitative retrograde double labeling study. Neuroscience 171:351-365.

Topolovec JC, Gati JS, Menon RS, Shoemaker JK, Cechetto DF (2004) Human cardiovascular and gustatory brainstem sites observed by functional magnetic resonance imaging. J Comp Neurol 471:446-461.

Tupone D, Madden CJ, Morrison SF (2013) Central activation of the Al adenosine receptor (A1AR) induces a hypothermic, torpor-like state in the rat. J Neurosci 33:14512-14525.

Tupone D, Cano G, Morrison SF (2017) Thermoregulatory inversion: a novel thermoregulatory paradigm. Am J Physiol Regul Integr Comp Physiol 312:R779-R786.

Tupone D, Cano G, Conceicao EP, Morrison SF (2018) Neural circuitry underlying thermal afferent influences during thermoregulatory inversion. FASEB J 32(1 Suppl):592.1.

Uddin O, Studlack P, Akintola T, Raver C, Castro A, Masri R, Keller A (2018) Amplified parabrachial nucleus activity in a rat model of trigeminal neuropathic pain. Neurobiol Pain 3:22-30.

White N, Franklin K (1989) The neural basis of reward and reinforcement. Neurosci Biobehav Rev 13:59-186.

Wu Q, Clark MS, Palmiter RD (2012) Deciphering a neuronal circuit that mediates appetite. Nature 483:594-597.

Yamamoto T, Shimura T, Sakai N, Ozaki N (1994) Representation of hedonics and quality of taste stimuli in the parabrachial nucleus of the rat. Physiol Behav 56:1197-1202.

Yasui Y, Saper CB, Cechetto DF (1989) Calcitonin gene-related peptide immunoreactivity in the visceral sensory cortex, thalamus, and related pathways in the rat. J Comp Neurol 290:487-501.

Youssef AM, Macefield VG, Henderson LA (2016) Pain inhibits pain; human brainstem mechanisms. Neuroimage 124:54-62. 